\title{
New Analytical Model of Spur Gears with 5 DOF Shafts and its Comparison with Other DOF Models
}

\author{
Łukasz Jedliński' \\ 1 Lublin University of Technology, ul. Nadbystrzycka 36, 20-618 Lublin, Poland \\ email: I.jedlinski@pollub.pl
}

\begin{abstract}
This study relates to the research on improving analytical models of gears. A new analytical model of gear shaft with 5 DOF was proposed. Equations of vibration were derived without small-angle approximation and were presented in a form that could be implemented in Simulink. In order to determine the effect of the additional DOF, four popular models having $2 \mathrm{DOF}, 4 \mathrm{DOF}, 6 \mathrm{DOF}$ and $8 \mathrm{DOF}$ were investigated, too. The proposed model has 12 DOF in total. This number of DOF could be increased; this, however, would result in a greater difference between the considered models, thus making it more difficult to evaluate the impact of the additional DOF of shafts. As a benchmark, the dynamic meshing force in the considered analytical models was calculated. Simulations were carried out with and without friction. Additionally, for the 12 DOF model, the effects of the position of the centre of gear and the centre of mass were investigated.
\end{abstract}

Keywords: dynamic meshing force, 5 DOF shafts, analytical gear model, multi DOF, gear model comparison, Simulink equations

\section{INTRODUCTION}

Analytical models of gears and gearboxes have one particular advantage over numerical models such as finite element analysis (FEA): they require a considerably shorter computational time. This results from that fact that far fewer equations must be solved. As a consequence, however, the level of details that can be modelled is more limited. The current trend regarding analytical and other models is to increase their accuracy. The review of the literature on analytical gear models shows that more recent studies focus, among others, on modelling gear tooth stiffness $[1,2]$, tooth damage $[3,4]$, macro geometry optimization [5], windage power losses [6], tooth root stress [7], tooth deflection [8], wear [9], friction and power loss [10], multi DOF models $[11,12]$. Increasing the number of DOF is one of the fundamental directions in the development of gear models.

The first gear model was developed by Touplin in 1950; it had 1 DOF and consisted of a spring, equivalent mass and wedge [13]. Later in that decade, the models with tooth compliance were developed, with gears having 2 DOF. In order to ensure more accurate prediction and modelling of the gear dynamics, stiffness of shafts and bearings was added. As a result, the number of DOF could be increased to 3 or 4, which in 1970 led to the creation of a model with 6 DOF [13]. In the 21 st century, a gear model with 16 DOF [14] was developed. The review of the publications available in Science Direct reveals that there is an analytical model of single-stage spur gear with as many as 19 DOF [11].

Multi DOF analytical models can imitate the operation of all basic components, such as gears, shafts, bearings and couplings [14, 15, 16, 17]. The main objective of this study was to create an analytical model of gears enabling a more precise description of rigid shaft motion. This was done through an example of single stage spur gears. Each shaft has 5 DOF. Revolution about the shaft axis is modelled by 1 DOF and there are 
2 translation (or one rotation and one translation) DOF in two perpendicular planes parallel to the LOA (line of action) and the OLOA (off-line of action) axis. The final and non-modelled DOF is the translation along the shaft axis. This motion is important in the case of helical gears, and, if necessary, it can be added relatively easily using the presented method. The derived equations do not contain small-angle approximations in the case of planar motion. Additionally, there is no assumption that gears must be located in the centre of bearings, and the centre of mass $(\mathrm{CoM})$ can be located in a different position than the gears. In previous studies, e.g. [18, 11, 12, 14], in which the shaft was supported between two bearings, the description of shaft motion is more simplified and does not cover the above-mentioned assumptions.

Although multi DOF models can simulate gear operation more accurately, recent studies still use analytical models of gears that have at least 2 DOF. Neubauer et al. [19] analysed noise reduction based on dynamic force by using a 2 DOF model. Dynamic meshing force was modelled in a $6 \mathrm{DOF}$ face-gear drive by Zhu et al. [20]. The effect of signal modulation was investigated with the use of a 2 DOF model [21]. Another study was carried out to model the gears with shafts supported by journal bearings based on a $5 \mathrm{DOF}$ analytical model [22]. It should be noted that researchers have been testing new ideas in models that have different numbers of DOF, which - undoubtedly - affects the results. In most cases, the dynamic meshing force is a source of vibration, noise and degradation of gears and other components. In this study, the influence of the number of DOF on the dynamic meshing force was investigated. The proposed new model with 12 DOF was compared with other popular models that have 2, 4, 6 and $8 \mathrm{DOF}$. When the meshing friction force is not considered, the number of DOF in the models with 6,8 and $12 \mathrm{DOF}$ is reduced to 4 , 6 and 8 DOF. The number of DOF in the proposed model could be increased, e.g. to 20 DOF by adding stiffness between gears and shafts and torsional stiffness of shafts. This, however, would result in a greater difference between the compared models, thus making it more difficult to evaluate the effect of additional DOF of shafts.

\section{Dynamic analytical model of spur gear with 5 DOF shafts}

The proposed model consists of a motor, motor coupling, spur gear, device coupling and output device (Fig. 1). The spur gear is comprised of a pinion, shaft and half of motor coupling treated as one rigid body (pinion subassembly), gear, shaft and half of device coupling treated as one rigid body (gear subassembly) and four bearings. The motor generates a constant input torque that is transmitted to the pinion by the motor coupling. The pinion drives the gear and output device by device coupling. The shafts and rotors make torsional vibration due to finite stiffness and damping of the coupling and gear teeth, according to the following equations:

\section{Equations of torsional vibration}

$$
\begin{gathered}
I_{m} \ddot{\varphi}_{m}+M_{c m}+M_{k m}=T_{m} \\
I_{p} \ddot{\varphi}_{p}+M_{c p}+M_{k p}=M_{c m}+M_{k m}+M_{f p}
\end{gathered}
$$

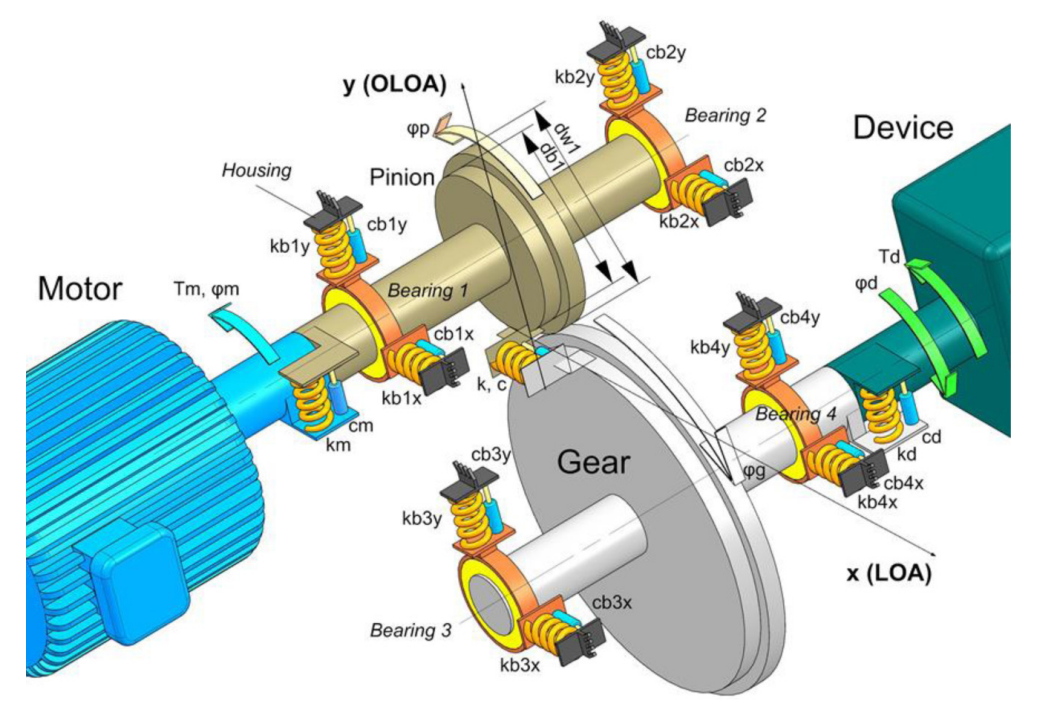

Fig. 1. Analytical 12 DOF model of single spur gear with motor and output device (break) 


$$
\begin{gathered}
I_{g} \ddot{\varphi}_{g}+M_{c d}+M_{k d}+M_{f g}=M_{c g}+M_{k g} \\
I_{d} \ddot{\varphi}_{d}+T_{d}=M_{c d}+M_{k d}
\end{gathered}
$$

The bearings enable the shafts to vibrate in planes parallel to the LOA $(x)$ axis and pass through the axis of shaft rotation (Figures 2 and 3 ). The normal meshing force is a source of this excitation. Free body diagrams used to create equations from (5) through (8) are given in Figs. 2 and 3. The equations describing the shaft and gear motion in the planes parallel to the LOA $(x)$ axis are as follows:

The equations of vibration in plane parallel to $\operatorname{LOA}(x)$

$$
\begin{gathered}
F_{k b 1 x} l_{p}+F_{c b 1 x} l_{p}+m_{p} \ddot{x}_{p C o M}\left(l_{p}-l_{p 2}\right)- \\
-I_{p x} \ddot{\theta}_{p x}=F_{n}\left(l_{p}-l_{p 1}\right) \\
F_{k b 2 x} l_{p}+F_{c b 2 x} l_{p}+m_{p} \ddot{x}_{p C o M} l_{p 2}+ \\
+I_{p x} \ddot{\theta}_{p x}=F_{n} l_{p 1} \\
F_{k b 3 x} l_{g}+F_{c b 3 x} l_{g}+m_{g} \ddot{x}_{g C o M}\left(l_{g}-l_{g 2}\right)+ \\
+I_{g x} \ddot{\theta}_{g x}=F_{n}\left(l_{g}-l_{g 1}\right) \\
F_{k b 4 x} l_{g}+F_{c b 4 x} l_{g}+m_{g} \ddot{x}_{g C o M} l_{g 2}- \\
-I_{g x} \ddot{\theta}_{g x}=F_{n} l_{g 1}
\end{gathered}
$$

Moreover, the bearings enable the shafts to vibrate in the planes parallel to the $\operatorname{OLOA}(y)$ axis and pass through the axis of shaft rotation. The variable tooth friction force is a source of this

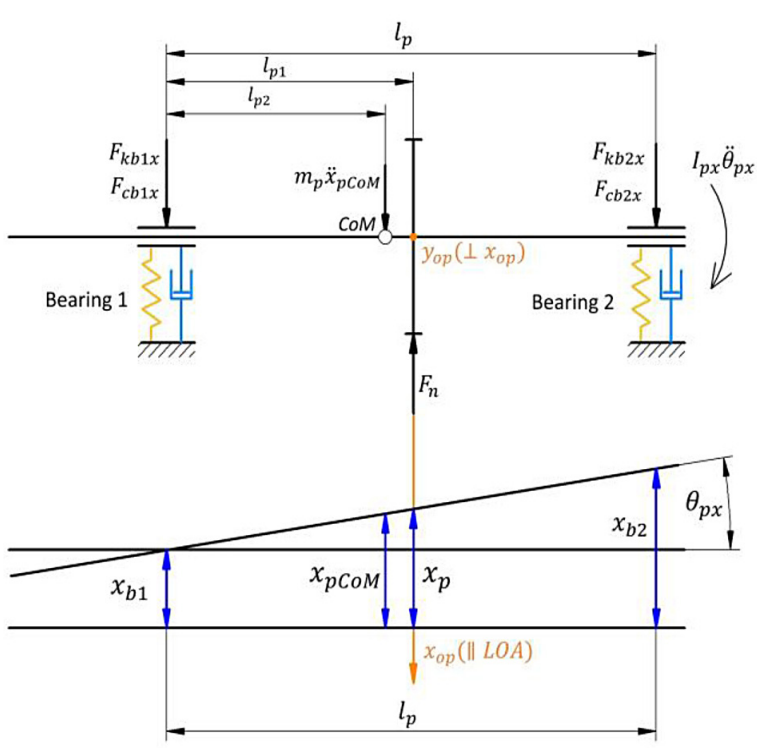

Fig. 2. Free body diagram on plane defined by the $x_{o p}(\| L O A)$ axis and pinion axis of rotation excitation. The equations describing the shaft and gear motion in the planes parallel to the OLOA (y) axis are as follows:

The equations of vibration in plane parallel to $\operatorname{OLOA}(y)$

$$
\begin{gathered}
F_{k b 1 y} l_{p}+F_{c b 1 y} l_{p}+m_{p} \ddot{y}_{p C o M}\left(l_{p}-l_{p 2}\right)- \\
-I_{p y} \ddot{\theta}_{p y}=F_{f}\left(l_{p}-l_{p 1}\right) \\
F_{k b 2 y} l_{p}+F_{c b 2 y} l_{p}+m_{p} \ddot{y}_{p C o M} l_{p 2}+ \\
+I_{p y} \ddot{\theta}_{p y}=F_{f} l_{p 1} \\
F_{k b 3 y} l_{g}+F_{c b 3 y} l_{g}+m_{g} \ddot{y}_{g C o M}\left(l_{g}-l_{g 2}\right)+ \\
+I_{g y} \ddot{\theta}_{g y}=F_{f}\left(l_{g}-l_{g 1}\right) \\
F_{k b 4 y} l_{g}+F_{c b 4 y} l_{g}+m_{g} \ddot{y}_{g C o M} l_{g 2}- \\
-I_{g y} \ddot{\theta}_{g y}=F_{f} l_{g 1}
\end{gathered}
$$

In order to solve the above equations, it is necessary to determine the relationship between the motion of characteristic points on the shafts (bottom parts of drawings in Figures 2 and 3). The displacement of pinion $\chi_{p}$ and gear $\chi_{g}$ calculated based on the displacement of the bearings is equal to:

$$
\begin{gathered}
x_{p}=x_{b 1}+l_{p 1} \frac{x_{b 2}-x_{b 1}}{l_{p}} \\
x_{g}=x_{b 4}+\left(l_{g}-l_{g 1}\right) \frac{x_{b 3}-x_{b 4}}{l_{g}}
\end{gathered}
$$

Differential expressions (13) and (14) are obtained to describe the linear velocity of pinion $\dot{x}_{p}$ and gear $\dot{x}_{g}$ :

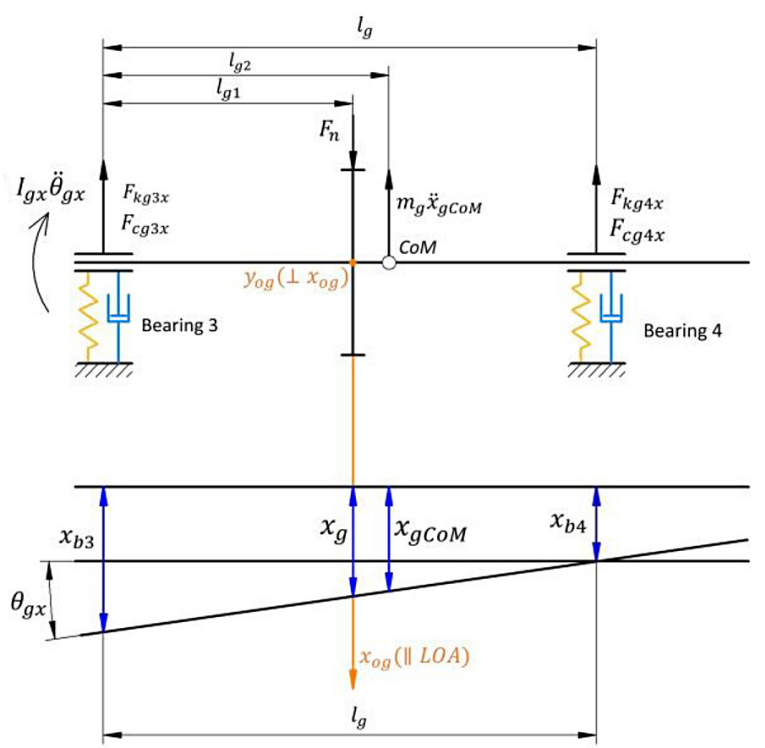

Fig. 3. Free body diagram on plane defined by the $x_{o g}(\| L O A)$ axis and gear axis of rotation 


$$
\begin{gathered}
\dot{x}_{p}=\dot{x}_{b 1}+l_{p 1} \frac{\dot{x}_{b 2}-\dot{x}_{b 1}}{l_{p}} \\
\dot{x}_{g}=\dot{x}_{b 4}+\left(l_{g}-l_{g 1}\right) \frac{\dot{x}_{b 3}-\dot{x}_{b 4}}{l_{g}}
\end{gathered}
$$

In a similar way, the linear acceleration of the CoM for both a rigid body consisting of a pinion, shaft and half of motor coupling $\ddot{x}_{p \text { Сом }}$ and $\ddot{y}_{p C o M}$ and for a rigid body composed of a gear, shaft and half of device coupling $\ddot{x}_{g \text { CоM }}$ and $\ddot{y}_{g C o M}$ is expressed as:

$$
\begin{gathered}
\ddot{x}_{p C o M}=\ddot{x}_{b 1}+\frac{l_{p 2}\left(\ddot{x}_{b 2}-\ddot{x}_{b 1}\right)}{l_{p}} \\
\ddot{y}_{p C o M}=\ddot{y}_{b 1}+\frac{l_{p 2}\left(\ddot{y}_{b 2}-\ddot{y}_{b 1}\right)}{l_{p}} \\
\ddot{x}_{g C O M}=\ddot{x}_{b 4}+\frac{\left(l_{g}-l_{g 2}\right)\left(\ddot{x}_{b 3}-\ddot{x}_{b 4}\right)}{l_{g}} \\
\ddot{y}_{g C o M}=\ddot{y}_{b 4}+\frac{\left(l_{g}-l_{g 2}\right)\left(\ddot{y}_{b 3}-\ddot{y}_{b 4}\right)}{l_{g}}
\end{gathered}
$$

Since the shafts with gears and couplings perform a planar motion, the relationship between angular acceleration and motion of the bearings must be established. First, the equations describing angular displacement are defined:

$$
\begin{aligned}
& \theta_{p x}=\sin ^{-1} \frac{x_{b 2}-x_{b 1}}{l_{p}} \\
& \theta_{p y}=\sin ^{-1} \frac{y_{b 2}-y_{b 1}}{l_{p}} \\
& \theta_{g x}=\sin ^{-1} \frac{x_{b 3}-x_{b 4}}{l_{g}} \\
& \theta_{g y}=\sin ^{-1} \frac{y_{b 3}-y_{b 4}}{l_{g}}
\end{aligned}
$$

By differentiating Equations (21-24) twice, the following accelerations are obtained:

$$
\begin{gathered}
\ddot{\theta}_{p x}=-\frac{\ddot{x}_{b 1}-\ddot{x}_{b 2}}{l_{p} \sqrt{1-\frac{\left(x_{b 1}-x_{b 2}\right)^{2}}{l_{p}^{2}}}}-\frac{\left(\dot{x}_{b 1}-\dot{x}_{b 2}\right)^{2}\left(x_{b 1}-x_{b 2}\right)}{l_{p}^{3}\left(1-\frac{\left(x_{b 1}-x_{b 2}\right)^{2}}{l_{p}^{2}}\right)^{\frac{3}{2}}} \\
\ddot{\theta}_{p y}=-\frac{\ddot{y}_{b 1}-\ddot{y}_{b 2}}{l_{p} \sqrt{1-\frac{\left(y_{b 1}-y_{b 2}\right)^{2}}{l_{p}^{2}}}}-\frac{\left(\dot{y}_{b 1}-\dot{y}_{b 2}\right)^{2}\left(y_{b 1}-y_{b 2}\right)}{l_{p}^{3}\left(1-\frac{\left(y_{b 1}-y_{b 2}\right)^{2}}{l_{p}^{2}}\right)^{\frac{3}{2}}}
\end{gathered}
$$

$$
\begin{gathered}
\ddot{\theta}_{g x}=\frac{\ddot{x}_{b 3}-\ddot{x}_{b 4}}{l_{p} \sqrt{1-\frac{\left(x_{b 3}-x_{b 4}\right)^{2}}{l_{g}^{2}}}}+\frac{\left(\dot{x}_{b 3}-\dot{x}_{b 4}\right)^{2}\left(x_{b 3}-x_{b 4}\right)}{l_{g}^{3}\left(1-\frac{\left(x_{b 3}-x_{b 4}\right)^{2}}{l_{g}^{2}}\right)^{\frac{3}{2}}} \\
\ddot{\theta}_{g y}=\frac{\ddot{y}_{b 3}-\ddot{y}_{b 4}}{l_{p} \sqrt{1-\frac{\left(y_{b 3}-y_{b 4}\right)^{2}}{l_{g}^{2}}}}+\frac{\left(\dot{y}_{b 3}-\dot{y}_{b 4}\right)^{2}\left(y_{b 3}-y_{b 4}\right)}{l_{g}^{3}\left(1-\frac{\left(y_{b 3}-y_{b 4}\right)^{2}}{l_{g}^{2}}\right)^{\frac{3}{2}}}
\end{gathered}
$$

Equations (13-28) were derived without small-angle approximations. The parameters of the analysed model are given in Tables 1 and 2.

Stiffness of teeth (Fig. 4) is obtained by the analytical model proposed by Cai [23]. In this model, the stiffness of one pair of teeth, $k_{S 1 \max }=418.72 \cdot 10^{6} \mathrm{~N} / \mathrm{m}$, is determined in accordance with ISO 6336-1.

Friction of the gear teeth was also considered using the Coulomb (sliding) friction model. The force of friction $F_{f}$ is calculated according to Equation (29). This force vector changes its sense in the pitch point (Fig. 5).

$$
F_{f}=\mu F_{n}
$$

where: $\mu=0.015$ is the coefficient of sliding friction used in the simulations.

The friction force acts at a distance from the centre of rotation of the gears, which produces frictional motion. A general formula is as follows:

$$
M_{f}=F_{f} r_{f}
$$

where: $r_{f}$ is the arm of the frictional moment simulated as variable in time [m]

For the purpose of clarity, the normal meshing force used for calculating the tooth friction force shown in Figure 5 has a constant value of $F_{n}=2000 \mathrm{~N}$. The main parameters of other components are given in Table 2.

\section{Analytical models of gears used for comparison purposes}

The models used for comparison purposes were described in this section. These models are very popular in the literature of the subject and have 2, 4, 6 and 8 DOF. Their parameters are the same as those used in the new model that were presented in Section 2. The equations and graphical representations of the employed models are given below. All models are based on a 2 DOF model. 
Table 1. Properties of gears

\begin{tabular}{|l|c|c|}
\hline \multicolumn{1}{|c|}{ Parameter } & Pinion & Gear \\
\hline Number of teeth & $z_{\mathrm{p}}=23$ & $z_{\mathrm{g}}=48$ \\
\hline Module [mm] & \multicolumn{2}{|c|}{$m=4$} \\
\hline Pressure angle [ ${ }^{\circ}$ ] & \multicolumn{2}{|c|}{$\alpha_{0}=20$} \\
\hline $\begin{array}{l}\text { Working } \\
\text { (operating) } \\
\text { pressure angle [ }{ }^{\circ} \text { ] }\end{array}$ & $\alpha_{\mathrm{w}}=17.61399$ \\
\hline Face width [mm] & \multicolumn{2}{|c|}{$b=40$} \\
\hline $\begin{array}{l}\text { Modification } \\
\text { coefficient }\end{array}$ & $x_{\mathrm{p}}=-0.1 \quad x_{\mathrm{g}}=-0.372$ \\
\hline Contact ratio & \multicolumn{2}{|c|}{$\varepsilon=1,78$} \\
\hline $\begin{array}{l}\text { Moment of inertia } \\
\text { (pinion/gear, shaft } \\
\text { and half of motor/ } \\
\text { device coupling) } \\
\text { [kgm }{ }^{2} \text { ] }\end{array}$ & $\begin{array}{c}I_{\mathrm{p}}=0.0033315 ; \\
I_{\mathrm{px}}=I_{\mathrm{py}}=\end{array}$ & $\begin{array}{c}I_{\mathrm{g}}=0.036831 ; \\
I_{\mathrm{gx}}=I_{\mathrm{gy}}=\end{array}$ \\
\hline $\begin{array}{l}\text { Mesh damping } \\
\text { [Ns/m] }\end{array}$ & \multicolumn{2}{|c|}{$c=40295635$} \\
\hline $\begin{array}{l}\text { Initial angular } \\
\text { speed [rad/s] }\end{array}$ & $\begin{array}{l}\mathrm{w}_{\mathrm{p}}=157,0796 \\
\left(n_{\mathrm{o}}=1500 \mathrm{rpm}\right)\end{array}$ & $\begin{array}{c}\mathrm{w}_{\mathrm{g}}=157.0796 / \\
(48 / 23)\end{array}$ \\
\hline
\end{tabular}

Table 2. Properties of other components

\begin{tabular}{|l|c|c|}
\hline \multicolumn{1}{|c|}{ Parameter } & Motor rotor & Device rotor \\
\hline $\begin{array}{l}\text { Moment of } \\
\text { inertia }\left[\mathrm{kgm}^{2}\right]\end{array}$ & $I_{\mathrm{m}}=0.075$ & $I_{\mathrm{d}}=0.12$ \\
\hline Torque $[\mathrm{Nm}]$ & $T_{\mathrm{m}}=63.66$ & $T_{\mathrm{d}}=132.85$ \\
\hline $\begin{array}{l}\text { Initial angular } \\
\text { speed }[\mathrm{rad} / \mathrm{s}]\end{array}$ & $\begin{array}{c}\omega_{\mathrm{m}}=157.0796\left(n_{\mathrm{m}}\right. \\
=1500 \mathrm{rpm})\end{array}$ & $\begin{array}{c}\omega_{\mathrm{d}}= \\
157.0796 /(48 / 23)\end{array}$ \\
\hline & Motor coupling & Device coupling \\
\hline Stiffness $[\mathrm{N} / \mathrm{m}]$ & $k_{m}=9.3 \cdot 10^{5}$ & $k_{d}=16.8 \cdot 10^{5}$ \\
\hline Damping [Ns/m] & $c_{m}=10$ & $c_{d}=10$ \\
\hline \multicolumn{3}{|c|}{ Bearings } \\
\hline Stiffness $[\mathrm{N} / \mathrm{m}]$ & $k_{b}=1.1 \cdot 10^{9}$ & \\
\hline Damping $[\mathrm{Ns} / \mathrm{m}]$ & $c_{b}=40$ & \\
\hline
\end{tabular}

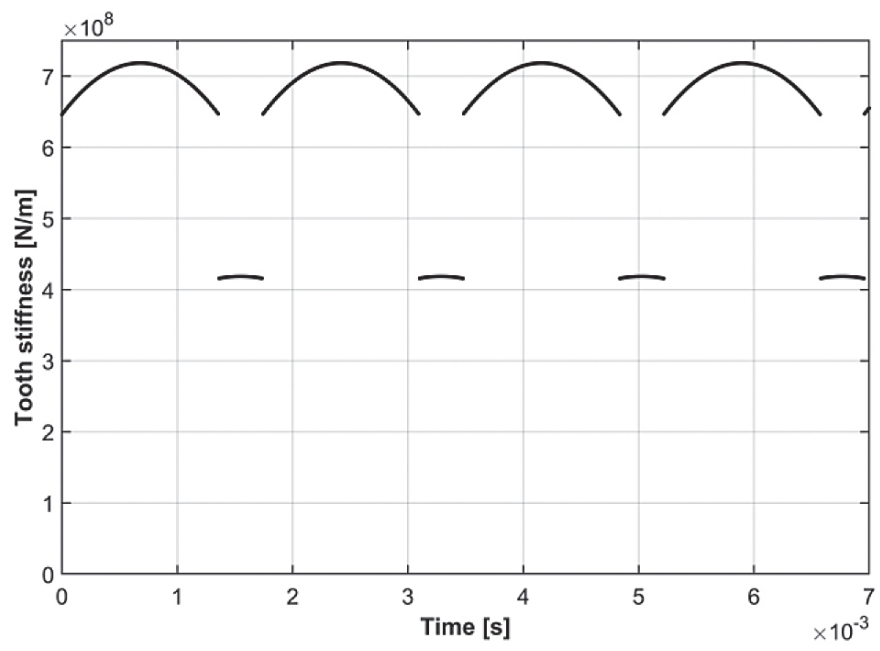

Fig. 4. Stiffness of teeth used in the simulations
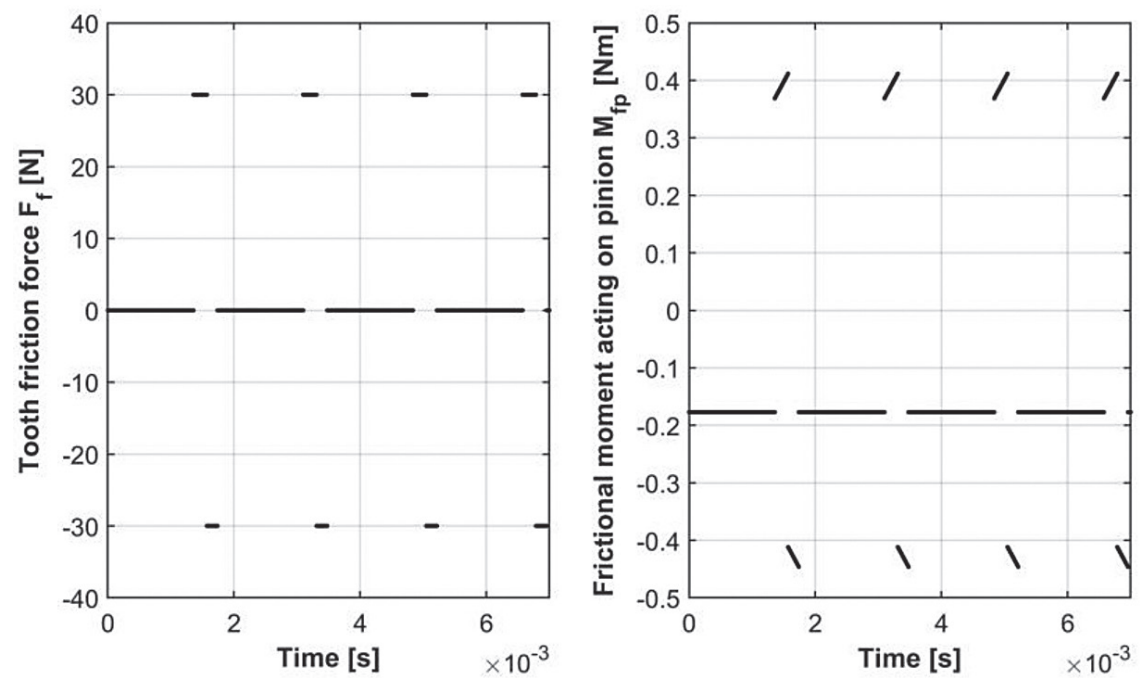

Fig. 5. Examples of diagrams showing friction force and frictional moment versus time (for a constant value of normal meshing force) 


\section{DOF model}

In this model, gears can rotate and vibrate independently about the axis of shaft rotation. The moments of inertia for the pinion $I_{\mathrm{p}}$ and the gear $I_{\mathrm{g}}$ are the same as those listed in Table 1.

Equations of torsional vibration

$$
\begin{gathered}
I_{p} \ddot{\varphi}_{p}+M_{c p}+M_{k p}=T_{m}+M_{f p} \\
I_{g} \ddot{\varphi}_{g}+T_{d}+M_{f g}=M_{c g}+M_{k g}
\end{gathered}
$$

\section{DOF model}

Compared to the previous model, the additional DOF are obtained by taking into account the couplers, motor and device rotor. All DOF describe rotation motion and torsional vibration.

Equations of torsional vibration

$$
\begin{gathered}
I_{m} \ddot{\varphi}_{m}+M_{c m}+M_{k m}=T_{m} \\
I_{p} \ddot{\varphi}_{p}+M_{c p}+M_{k p}=M_{c m}+M_{k m}+M_{f p} \\
I_{g} \ddot{\varphi}_{g}+M_{c d}+M_{k d}+M_{f g}=M_{c g}+M_{k g} \\
I_{d} \ddot{\varphi}_{d}+T_{d}=M_{c d}+M_{k d}
\end{gathered}
$$

\section{DOF model}

In order to obtain this model from the $2 \mathrm{DOF}$ model, gear translations were added. Each gear has 3 DOF and can perform lateral and torsional vibration. The bearing stiffness is twice higher than that of the bearings in the proposed model. In this way, the total stiffness is the same. If friction is not considered, the motion along the OLOA $(y)$ axis does not occur, and thus the model is reduced to $4 \mathrm{DOF}$.

\section{Equations of torsional vibration}

$$
\begin{aligned}
& I_{p} \ddot{\varphi}_{p}+M_{c p}+M_{k p}=T_{m}+M_{f p} \\
& I_{g} \ddot{\varphi}_{g}+T_{d}+M_{f g}=M_{c g}+M_{k g}
\end{aligned}
$$

Equations of vibration in the plane parallel to $\operatorname{LOA}(x)$

$$
\begin{aligned}
& m_{p} \ddot{x}_{p}+c_{b p x} \dot{x}_{p}+k_{b p x} x_{p}=F_{n} \\
& m_{g} \ddot{x}_{g}+c_{b g x} \dot{x}_{g}+k_{b g x} x_{g}=F_{n}
\end{aligned}
$$

Equations of vibration in the plane parallel to $\operatorname{OLOA}(y)$

$$
\begin{aligned}
& m_{p} \ddot{y}_{p}+c_{b p y} \dot{y}_{p}+k_{b p y} y_{p}=F_{f} \\
& m_{g} \ddot{y}_{g}+c_{b g y} \dot{y}_{g}+k_{b g y} y_{g}=F_{f}
\end{aligned}
$$

\section{DOF model}

Compared to the previous model, torsional vibrations of the motor and device rotor were added through couplings. If friction is not considered, the motion along the OLOA $(y)$ axis does not occur, and thus the model is reduced to $6 \mathrm{DOF}$.

Equations of torsional vibration

$$
\begin{gathered}
I_{m} \ddot{\varphi}_{m}+M_{c m}+M_{k m}=T_{m} \\
I_{p} \ddot{\varphi}_{p}+M_{c p}+M_{k p}=M_{c m}+M_{k m}+M_{f p} \\
I_{g} \ddot{\varphi}_{g}+M_{c d}+M_{k d}+M_{f g}=M_{c g}+M_{k g} \\
I_{d} \ddot{\varphi}_{d}+T_{d}=M_{c d}+M_{k d}
\end{gathered}
$$

Equations of vibration in the plane parallel to $\operatorname{LOA}(x)$

$$
m_{p} \ddot{x}_{p}+c_{b p x} \dot{x}_{p}+k_{b p x} x_{p}=F_{n}
$$

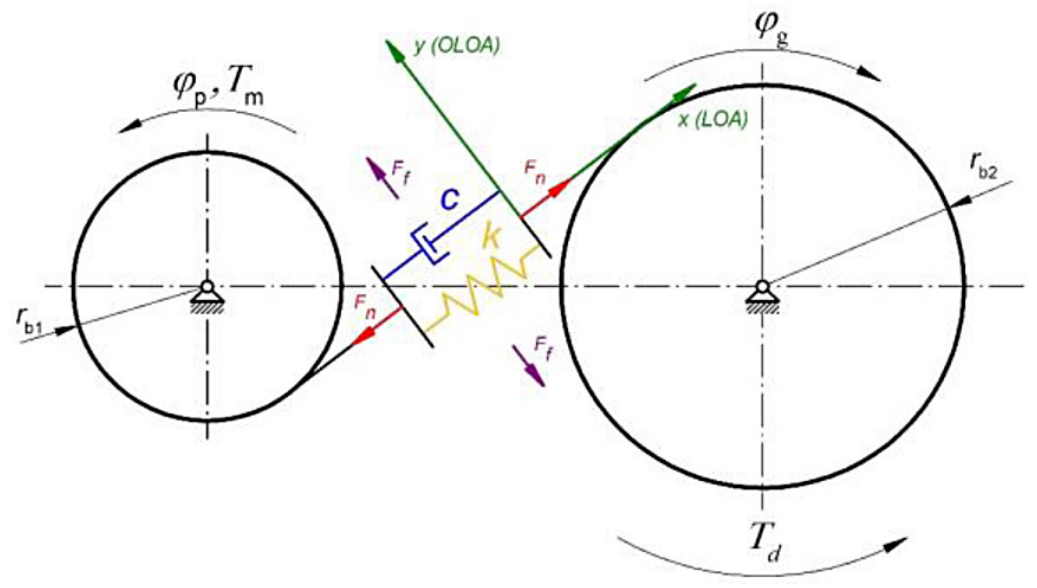

Fig. 6. 2 DOF model 


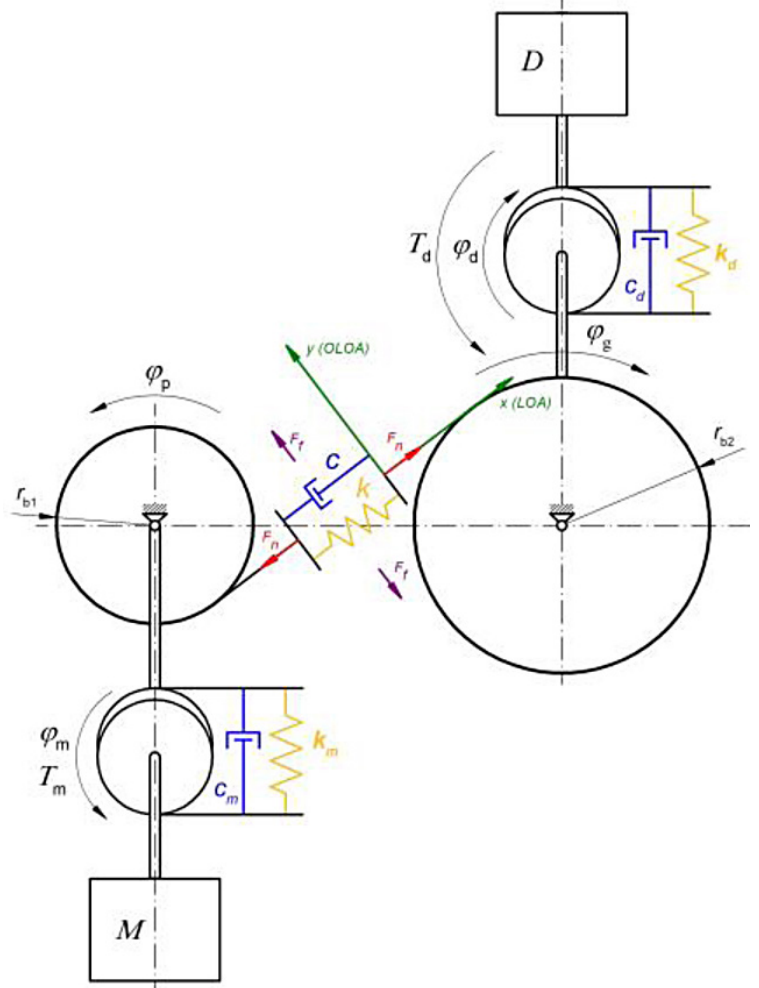

Fig. 7. 4 DOF model

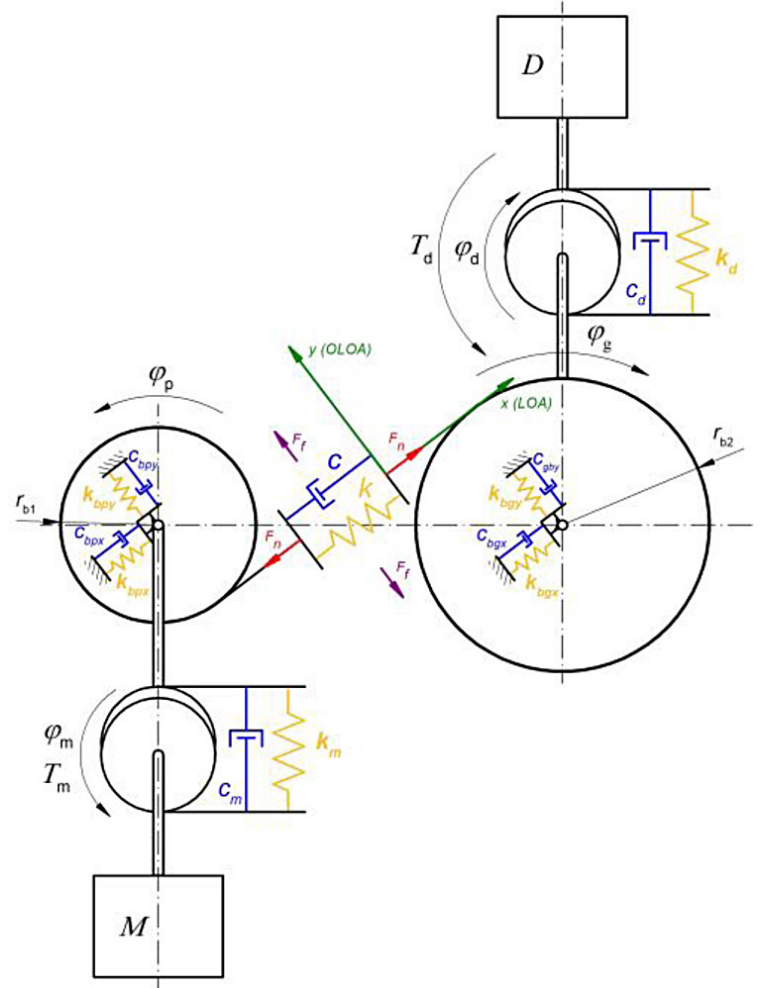

Fig. 9. 8 DOF model

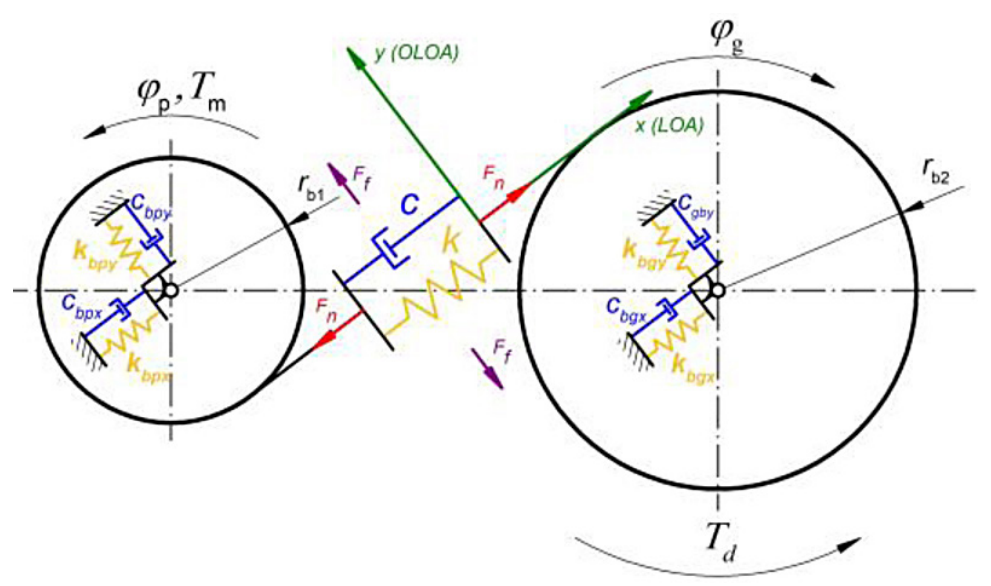

Fig. 8. 6 DOF model

$$
m_{g} \ddot{x}_{g}+c_{b g x} \dot{x}_{g}+k_{b g x} x_{g}=F_{n}
$$

Equations of vibration in the plane parallel to $\operatorname{OLOA}(y)$

$$
\begin{aligned}
& m_{p} \ddot{y}_{p}+c_{b p y} \dot{y}_{p}+k_{b p y} y_{p}=F_{f} \\
& m_{g} \ddot{y}_{g}+c_{b g y} \dot{y}_{g}+k_{b g y} y_{g}=F_{f}
\end{aligned}
$$

\section{Numerical calculations of dynamic meshing force}

All models were used to find the value of the dynamic meshing force $F_{d}$ for stable vibration. The
Simulink and Matlab environments, in combination with the Runge-Kutta method $(4,5)$ were employed to solve the equations. The solver's absolute tolerance was set to 1 e- 8 and the maximum step was 1e-5.

Figure 10 shows the results of five models for two considered variants: with and without tooth friction. The coefficient of sliding friction is equal to $\mu=0.015$, which results in a low value of the friction force. In effect, the dynamic meshing force value does not differ to a significant extent. Similar results were obtained for the models with 4 and 8 DOF, and the same situation can be observed for the three remaining models. In 


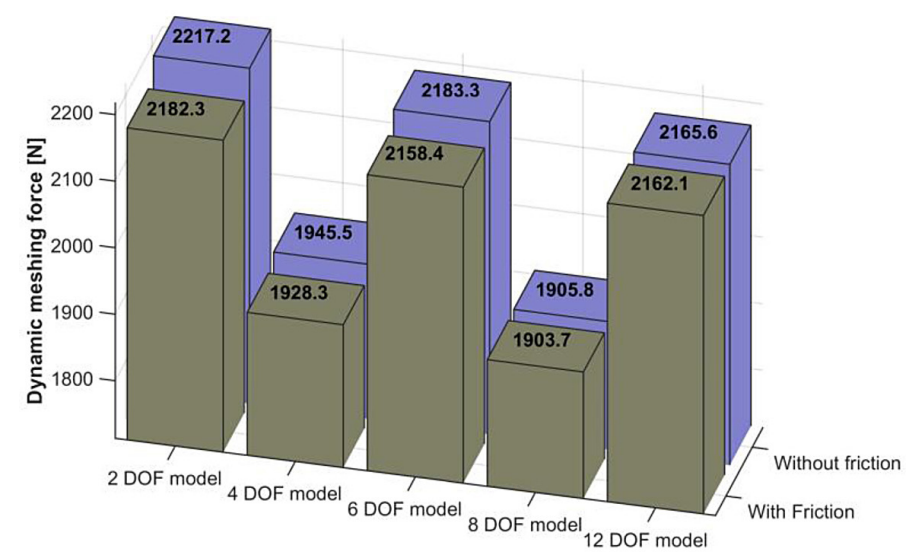

Fig. 10. Dynamic meshing force calculated with and without friction

this simulation, the gears and CoM are located in the centre of the bearings in the 12 DOF model $\left(l_{p}=l_{g}=2 l_{p 1}=2 l_{p 2}=2 l_{g 1}=2 l_{g 2}\right)$.

The assumption that gears are located in the centre of bearings in a real structure is usually valid. The same is, however, rarely true with respect to the CoM of shafts or - like in the case in question - the CoM of shaft, pinion/gear and half of coupling treated as one body. This is because one end of the shaft extends outside the bearing to enable the connection with other members of the drive system. This particular case of an asymmetric position of the CoM was also analysed in this study (Figs. 11 and 12). Gears are always located in the centre of bearings $\left(l_{p}=l_{g}=2 l_{p 1}=2 l_{g 1}\right)$. The CoM of the pinion and gear subassembly is displaced about a certain value that is calculated as: $l_{p 1}-l_{p 2}=l_{g 2}-l_{g 1}$. In the first analysis, the distance was changed every $0.002 \mathrm{~m}$ (Fig. 11). The dynamic meshing force increases in a similar way to the exponential diagram.
In the second analysis (Fig. 12), the distance was changed every $0.01 \mathrm{~m}$. The results are not monotonic. The maximum value of the dynamic meshing force was achieved for the $0.01 \mathrm{~m}$ distance and it decreased with increasing distance. Figure 13 shows the spectra of pinion torsional vibration for the same models as those shown in Figure 10. The influence of friction is not significant because the vibrations are stable and the sliding friction coefficient is low. For the models having from 2 to $8 \mathrm{DOF}$, the dominant frequency is $4025 \mathrm{~Hz}$. For the $12 \mathrm{DOF}$ model, this frequency is equal to $5175 \mathrm{~Hz}$.

\section{CONCLUSIONS}

This study investigated the influence of the number of modelled DOF on the dynamic meshing force (Fig. 10), demonstrating that the addition of rotational DOF and the consideration of couplings and rotors in outside machines are of

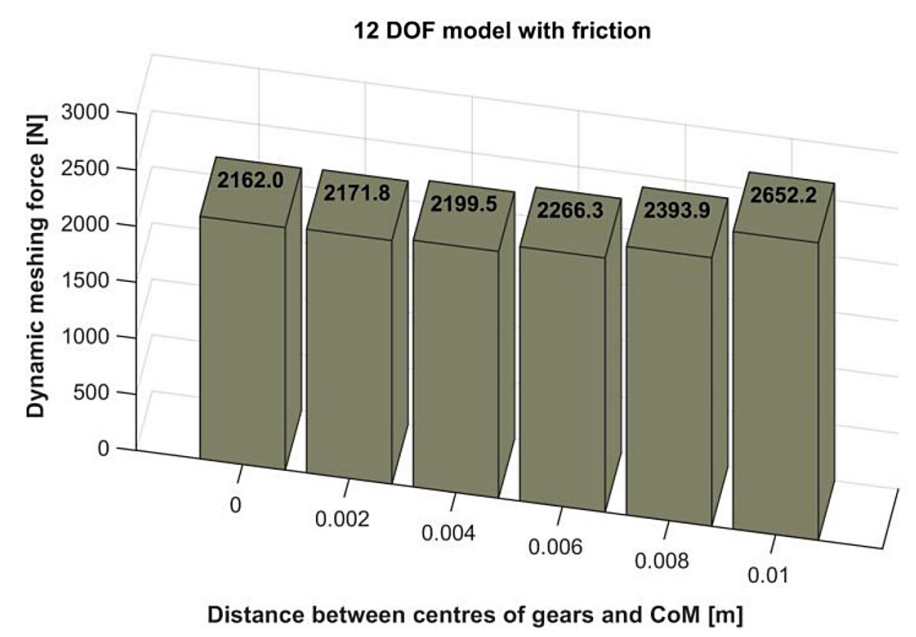

Fig. 11. Dynamic meshing force calculated for the 12 DOF model with the distance between the centre of gears and the CoM ranging from 0 to $0.01 \mathrm{~m}$ 


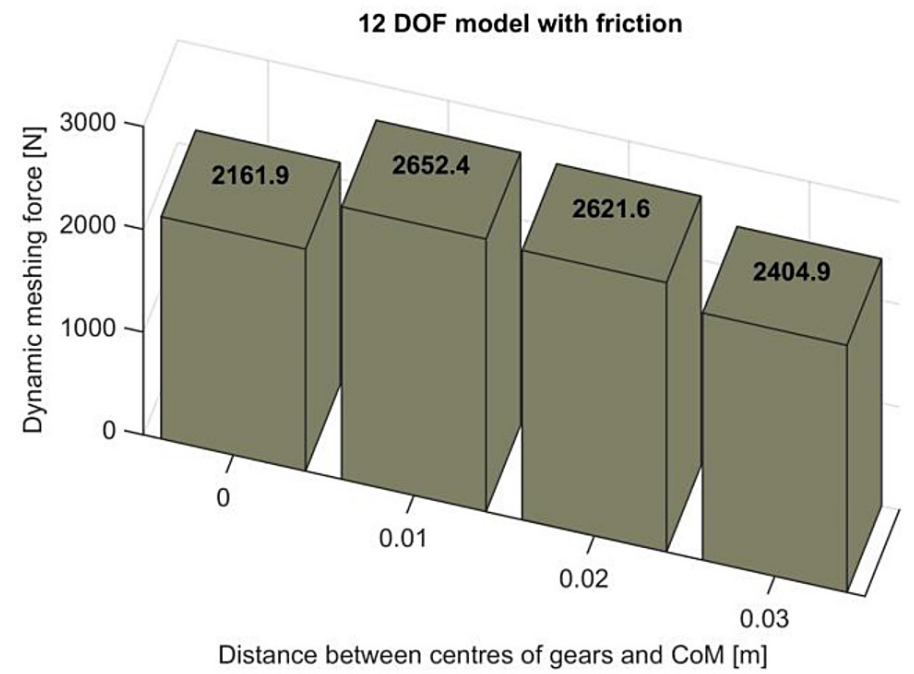

Fig. 12. Dynamic meshing force calculated for the 12 DOF model with the distance between the centre of gears and the CoM ranging from 0 to $0.03 \mathrm{~m}$
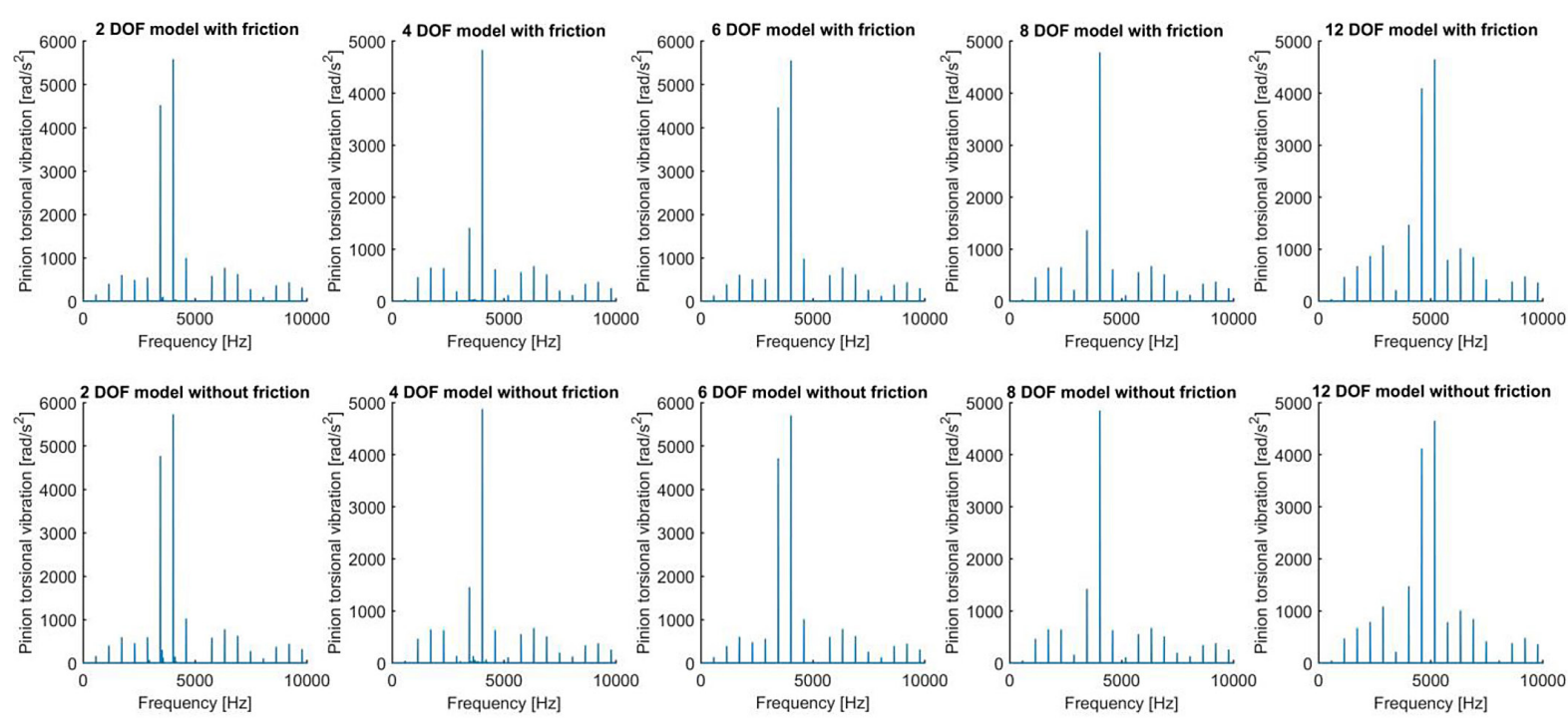

Fig. 13. Spectrum of torsional vibration in models with different numbers of DOF

significant importance for the models. This concerns the models with $4 \mathrm{DOF}$ and $8 \mathrm{DOF}$, as they have considerably lower values of the dynamic meshing force than the models with 2 DOF and 6 DOF. The moments of inertia of rotors in outside machines are usually higher than those of shafts and gears, which accounts for the differences. The 12 DOF model also contains the rotational DOF, but the dynamic meshing force is higher, which is caused by the additional DOF of the shafts. Each shaft has 5 DOF. The spatial motion is modelled more accurately, which has a significant impact on the gear dynamics. The proposed model also makes it possible to describe the spatial position of forces and moments in a more precise manner. The influence of the distance between the centre of gears and the CoM was analysed (Figs. 11 and 12). It was found that the relationship is not monotonic and is of significant importance.

Interesting results were also obtained when 4 DOF connected with shaft motion were added to the models with 2 DOF (Fig. 6) and 4 DOF (Fig. 7), thus yielding the models with 6 DOF (Fig. 8) and 8 DOF (Fig. 9). The difference in the dynamic meshing force between the 2 DOF and 6 DOF models and between the 4 DOF and 8 DOF models is not that significant (Fig. 10).

In this study, the influence of different numbers of DOF in gear models on the dynamic meshing force was investigated. The proposed new model allows for a more precise description of shaft motion, which distinguishes it from the previous models. 
Appendix A. Dynamic equations of the proposed 12 DOF model converted to the form that could be implemented in Simulink

$$
\begin{aligned}
& \ddot{\varphi}_{m}=\left[T_{m}-c_{m} r_{m}\left(\dot{\varphi}_{m}-\dot{\varphi}_{p}\right)-k_{m} r_{m}\left(\varphi_{m}-\varphi_{p}\right)\right] \frac{1}{I_{m}} \\
& \ddot{\varphi}_{p}=\left[c_{m} r_{m}\left(\dot{\varphi}_{m}-\dot{\varphi}_{p}\right)+k_{m} r_{m}\left(\varphi_{m}-\varphi_{p}\right)+M_{f p}\right. \\
& +k r_{b 1}\left(\varphi_{g} r_{b 2}-\varphi_{p} r_{b 1}-x_{b 4}-x_{b 1}+\frac{l_{p 1}\left(x_{b 1}-x_{b 2}\right)}{l_{p}}-\frac{\left(l_{g}-l_{g 1}\right)\left(x_{b 3}-x_{b 4}\right)}{l_{g}}\right) \\
& \left.+c r_{b 1}\left(\dot{\varphi}_{g} r_{b 2}-\dot{\varphi}_{p} r_{b 1}-\dot{x}_{b 4}-\dot{x}_{b 1}+\frac{l_{p 1}\left(\dot{x}_{b 1}-\dot{x}_{b 2}\right)}{l_{p}}-\frac{\left(l_{g}-l_{g 1}\right)\left(\dot{x}_{b 3}-\dot{x}_{b 4}\right)}{l_{g}}\right)\right] \frac{1}{I_{p}} \\
& \ddot{\varphi}_{g}=\left[c_{d} r_{d}\left(\dot{\varphi}_{d}-\dot{\varphi}_{g}\right)+k_{d} r_{d}\left(\varphi_{d}-\varphi_{g}\right)-M_{f g}\right. \\
& -k r_{b 2}\left(\varphi_{g} r_{b 2}-\varphi_{p} r_{b 1}-x_{b 4}-x_{b 1}+\frac{l_{p 1}\left(x_{b 1}-x_{b 2}\right)}{l_{p}}-\frac{\left(l_{g}-l_{g 1}\right)\left(x_{b 3}-x_{b 4}\right)}{l_{g}}\right) \\
& \left.-c r_{b 2}\left(\dot{\varphi}_{g} r_{b 2}-\dot{\varphi}_{p} r_{b 1}-\dot{x}_{b 4}-\dot{x}_{b 1}+\frac{l_{p 1}\left(\dot{x}_{b 1}-\dot{x}_{b 2}\right)}{l_{p}}-\frac{\left(l_{g}-l_{g 1}\right)\left(\dot{x}_{b 3}-\dot{x}_{b 4}\right)}{l_{g}}\right)\right] \frac{1}{I_{g}} \\
& \ddot{\varphi}_{d}=\left[c_{d} r_{d}\left(\dot{\varphi}_{g}-\dot{\varphi}_{d}\right)+k_{d} r_{d}\left(\varphi_{g}-\varphi_{d}\right)-T_{d}\right] \frac{1}{I_{d}} \\
& \ddot{x}_{b 1}=\left\{k k\left(\varphi_{g} r_{b 2}-\varphi_{p} r_{b 1}-x_{b 4}-x_{b 1}+\frac{l_{p 1}\left(x_{b 1}-x_{b 2}\right)}{l_{p}}-\frac{\left(l_{g}-l_{g 1}\right)\left(x_{b 3}-x_{b 4}\right)}{l_{g}}\right)\right. \\
& \left.+c\left(\dot{\varphi}_{g} r_{b 2}-\dot{\varphi}_{p} r_{b 1}-\dot{x}_{b 1}-\dot{x}_{b 4}+\frac{l_{p 1}\left(\dot{x}_{b 1}-\dot{x}_{b 2}\right)}{l_{p}}-\frac{\left(\dot{x}_{b 3}-\dot{x}_{b 4}\right)\left(l_{g}-l_{g 1}\right)}{l_{g}}\right)\right]\left(l_{p}-l_{p 1}\right) \\
& -I_{p x}\left(\frac{\ddot{x}_{b 2}}{l_{p} \sqrt{1-\frac{\left(x_{b 1}-x_{b 2}\right)^{2}}{l_{p}^{2}}}}-\frac{\left(\dot{x}_{b 1}-\dot{x}_{b 2}\right)^{2}\left(x_{b 1}-x_{b 2}\right)}{l_{p}^{3}\left(1-\frac{\left(x_{b 1}-x_{b 2}\right)^{2}}{l_{p}^{2}}\right)^{\frac{3}{2}}}\right)+l_{p} k_{b 1} x_{b 1}+l_{p} c_{b 1} \dot{x}_{b 1} \\
& \left.+\frac{l_{p 2} m_{p}\left(l_{p}-l_{p 2}\right) \ddot{x}_{b 2}}{l_{p}}\right\} \div\left[m_{p}\left(l_{p}-l_{p 2}\right)\left(\frac{l_{p 2}}{l_{p}}-1\right)-\frac{I_{p x}}{l_{p} \sqrt{1-\frac{\left(x_{b 1}-x_{b 2}\right)^{2}}{l_{p}^{2}}}}\right] \\
& \ddot{x}_{b 2}=\left\{l _ { p 1 } \left[k\left(\varphi_{g} r_{b 2}-\varphi_{p} r_{b 1}-x_{b 4}-x_{b 1}+\frac{l_{p 1}\left(x_{b 1}-x_{b 2}\right)}{l_{p}}-\frac{\left(l_{g}-l_{g 1}\right)\left(x_{b 3}-x_{b 4}\right)}{l_{g}}\right)\right.\right. \\
& \left.+c\left(\dot{\varphi}_{g} r_{b 2}-\dot{\varphi}_{p} r_{b 1}-\dot{x}_{b 1}-\dot{x}_{b 4}+\frac{l_{p 1}\left(\dot{x}_{b 1}-\dot{x}_{b 2}\right)}{l_{p}}-\frac{\left(\dot{x}_{b 3}-\dot{x}_{b 4}\right)\left(l_{g}-l_{g 1}\right)}{l_{g}}\right)\right]
\end{aligned}
$$

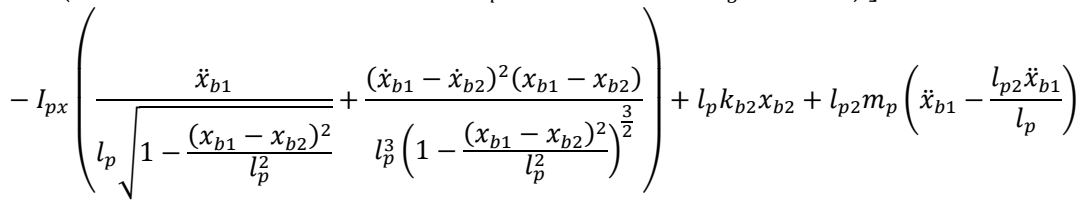

$$
\begin{aligned}
& \left.+l_{p} c_{b 2} \dot{x}_{b 2}\right\} \div\left(-\frac{I_{p x}}{l_{p} \sqrt{1-\frac{\left(x_{b 1}-x_{b 2}\right)^{2}}{l_{p}^{2}}}}-\frac{l_{p 2}^{2} m_{p}}{l_{p}}\right) \\
& \ddot{x}_{b 3}=\left\{\left[k\left(\varphi_{g} r_{b 2}-\varphi_{p} r_{b 1}-x_{b 4}-x_{b 1}+\frac{l_{p 1}\left(x_{b 1}-x_{b 2}\right)}{l_{p}}-\frac{\left(l_{g}-l_{g 1}\right)\left(x_{b 3}-x_{b 4}\right)}{l_{g}}\right)\right.\right. \\
& \left.+c\left(\dot{\varphi}_{g} r_{b 2}-\dot{\varphi}_{p} r_{b 1}-\dot{x}_{b 1}-\dot{x}_{b 4}+\frac{l_{p 1}\left(\dot{x}_{b 1}-\dot{x}_{b 2}\right)}{l_{p}}-\frac{\left(\dot{x}_{b 3}-\dot{x}_{b 4}\right)\left(l_{g}-l_{g 1}\right)}{l_{g}}\right)\right]\left(l_{g}-l_{g 1}\right)
\end{aligned}
$$




$$
\begin{aligned}
& -I_{g x}\left(\frac{\ddot{x}_{b 4}}{l_{g} \sqrt{1-\frac{\left(x_{b 3}-x_{b 4}\right)^{2}}{l_{g}^{2}}}}-\frac{\left(\dot{x}_{b 3}-\dot{x}_{b 4}\right)^{2}\left(x_{b 3}-x_{b 4}\right)}{l_{g}^{3}\left(1-\frac{\left(x_{b 3}-x_{b 4}\right)^{2}}{l_{g}^{2}}\right)^{\frac{3}{2}}}\right)+l_{g} k_{b 3} x_{b 3} \\
& \left.+m_{g}\left(\ddot{x}_{b 4}-\frac{\left(l_{g}-l_{g 2}\right) \ddot{x}_{b 4}}{l_{g}}\right)\left(l_{g}-l_{g 2}\right)+l_{g} c_{b 3} \dot{x}_{b 3}\right\} \div\left(-\frac{I_{g x}}{l_{g} \sqrt{1-\frac{\left(x_{b 3}-x_{b 4}\right)^{2}}{l_{g}^{2}}}}-\frac{m_{g}\left(l_{g}-l_{g 2}\right)^{2}}{l_{g}}\right) \\
& \ddot{x}_{b 4}=\left\{l _ { g 1 } \left[k\left(\varphi_{g} r_{b 2}-\varphi_{p} r_{b 1}-x_{b 4}-x_{b 1}+\frac{l_{p 1}\left(x_{b 1}-x_{b 2}\right)}{l_{p}}-\frac{\left(l_{g}-l_{g 1}\right)\left(x_{b 3}-x_{b 4}\right)}{l_{g}}\right)\right.\right. \\
& \left.+c\left(\dot{\varphi}_{g} r_{b 2}-\dot{\varphi}_{p} r_{b 1}-\dot{x}_{b 1}-\dot{x}_{b 4}+\frac{l_{p 1}\left(\dot{x}_{b 1}-\dot{x}_{b 2}\right)}{l_{p}}-\frac{\left(\dot{x}_{b 3}-\dot{x}_{b 4}\right)\left(l_{g}-l_{g 1}\right)}{l_{g}}\right)\right] \\
& -I_{g x}\left(\frac{\ddot{x}_{b 3}}{l_{g} \sqrt{1-\frac{\left(x_{b 3}-x_{b 4}\right)^{2}}{l_{g}^{2}}}}+\frac{\left(\dot{x}_{b 3}-\dot{x}_{b 4}\right)^{2}\left(x_{b 3}-x_{b 4}\right)}{l_{g}^{3}\left(1-\frac{\left(x_{b 3}-x_{b 4}\right)^{2}}{l_{g}^{2}}\right)^{\frac{3}{2}}}\right)+l_{g} k_{b 4} x_{b 4}+l_{g} c_{b 4} \dot{x}_{b 4} \\
& \left.+\frac{l_{g 2} m_{g}\left(l_{g}-l_{g 2}\right) \ddot{x}_{b 3}}{l_{g}}\right\} \div\left(l_{g 2} m_{g}\left(\frac{l_{g}-l_{g 2}}{l_{g}}-1\right)-\frac{I_{g x}}{l_{g} \sqrt{1-\frac{\left(x_{b 3}-x_{b 4}\right)^{2}}{l_{g}^{2}}}}\right) \\
& =\frac{l_{p} k_{b 1} y_{b 1}-F_{f}\left(l_{p}-l_{p 1}\right)-I_{p y}\left(\frac{\ddot{y}_{b 2}}{\left.l_{p} \sqrt{1-\frac{\left(y_{b 1}-y_{b 2}\right)^{2}}{l_{p}^{2}}}-\frac{\left(\dot{y}_{b 1}-\dot{y}_{b 2}\right)^{2}\left(y_{b 1}-y_{b 2}\right)}{l_{p}^{3}\left(1-\frac{\left(y_{b 1}-y_{b 2}\right)^{2}}{l_{p}^{2}}\right)^{\frac{3}{2}}}\right)+l_{p} c_{b 1} \dot{y}_{b 1}+\frac{l_{p 2} m_{p}\left(l_{p}-l_{p 2}\right) \ddot{y}_{b 2}}{l_{p}}}\right.}{m_{p}\left(l_{p}-l_{p 2}\right)\left(\frac{l_{p 2}}{l_{p}}-1\right)-\frac{I_{p y}}{l_{p} \sqrt{1-\frac{\left(y_{b 1}-y_{b 2}\right)^{2}}{l_{p}^{2}}}}} \\
& \ddot{y}_{b 2}=\frac{l_{p} k_{b 2} y_{b 2}-F_{f} l_{p 1}-I_{p y}\left(\frac{\ddot{y}_{b 1}}{\left.l_{p} \sqrt{1-\frac{\left(y_{b 1}-y_{b 2}\right)^{2}}{l_{p}^{2}}}+\frac{\left(\dot{y}_{b 1}-\dot{y}_{b 2}\right)^{2}\left(y_{b 1}-y_{b 2}\right)}{l_{p}^{3}\left(1-\frac{\left(y_{b 1}-y_{b 2}\right)^{2}}{l_{p}^{2}}\right)^{\frac{3}{2}}}\right)+l_{p 2} m_{p}\left(\ddot{y}_{b 1}-\frac{l_{p 2} \ddot{y}_{b 1}}{l_{p}}\right)+l_{p 2} c_{b 2} \dot{y}_{b 2}}\right.}{-\frac{l_{p y}}{l_{p} \sqrt{1-\frac{\left(y_{b 1}-y_{b 2}\right)^{2}}{l_{p}^{2}}}}-\frac{l_{p 2}^{2} m_{p}}{l_{p}}} \\
& \ddot{y}_{b 3}=\frac{l_{g} k_{b 3} y_{b 3}-F_{f}\left(l_{g}-l_{g 1}\right)-I_{g y}\left(\frac{\ddot{y}_{b 4}}{l_{g} \sqrt{1-\frac{\left(y_{b 3}-y_{b 4}\right)^{2}}{l_{g}^{2}}}}-\frac{\left(\dot{y}_{b 3}-\dot{y}_{b 4}\right)^{2}\left(y_{b 3}-y_{b 4}\right)}{l_{g}^{3}\left(1-\frac{\left(y_{b 3}-y_{b 4}\right)^{2}}{l_{g}^{2}}\right)^{\frac{3}{2}}}\right)+m_{g}\left(\ddot{y}_{b 4}-\frac{\left(l_{g}-l_{g 2}\right) \ddot{y}_{b 4}}{l_{g}}\right)\left(l_{g}-l_{g 2}\right)+l_{g} c_{b 3} \dot{y}_{b 3}}{-\frac{m_{g}\left(l_{g}-l_{g 2}\right)^{2}}{l_{g}}-\frac{I_{g y}}{l_{g} \sqrt{1-\frac{\left(y_{b 3}-y_{b 4}\right)^{2}}{l_{g}^{2}}}}} \\
& \ddot{y}_{b 4}=\frac{l_{g} k_{b 4} y_{b 4}-F_{f} l_{g 1}-I_{g y}\left(\frac{\ddot{y}_{b 3}}{l_{g} \sqrt{1-\frac{\left(y_{b 3}-y_{b 4}\right)^{2}}{l_{g}^{2}}}}+\frac{\left(\dot{y}_{b 3}-\dot{y}_{b 4}\right)^{2}\left(y_{b 3}-y_{b 4}\right)}{l_{g}^{3}\left(1-\frac{\left(y_{b 3}-y_{b 4}\right)^{2}}{l_{g}^{2}}\right)^{\frac{3}{2}}}\right)+l_{g} c_{b 4} \dot{y}_{b 4}+\frac{l_{g 2} m_{g}\left(l_{g}-l_{g 2}\right) \ddot{y}_{b 3}}{l_{g}}}{l_{g 2} m_{g}\left(\frac{l_{g}-l_{g 2}}{l_{g}}-1\right)-\frac{I_{g y}}{l_{g} \sqrt{1-\frac{\left(y_{b 3}-y_{b 4}\right)^{2}}{l_{g}^{2}}}}}
\end{aligned}
$$




\section{Nomenclature}

$T_{m}$-input motor torque $[\mathrm{Nm}]$

$T_{d}$ - output device torque $[\mathrm{Nm}]$

$I_{m}$ - mass moment of inertia of motor rotor and half of coupling $\left[\mathrm{kg} \cdot \mathrm{m}^{2}\right]$

$I_{p}$ - mass moment of inertia of pinion, shaft and half of coupling (pinion subassembly) $\left[\mathrm{kg} \cdot \mathrm{m}^{2}\right]$

$I_{g}$ - mass moment of inertia of gear, shaft and half of coupling (gear subassembly) $\left[\mathrm{kg} \cdot \mathrm{m}^{2}\right]$

$I_{d}$ - mass moment of inertia of device rotor and half of coupling $\left[\mathrm{kg} \cdot \mathrm{m}^{2}\right]$

$I_{p x}\left(I_{p x}=I_{p y}\right)$ - mass moment of inertia of pinion, shaft and half of coupling about $y_{o p}$ axis $\left[\mathrm{kg} \cdot \mathrm{m}^{2}\right]$

$I_{g x}\left(I_{g x}=I_{g y}\right)$ - mass moment of inertia of gear, shaft and half of coupling about the $y_{o g}$ axis $\left[\mathrm{kg} \cdot \mathrm{m}^{2}\right]$

$\ddot{\varphi}$ - angular acceleration [rad/ $\left.\mathrm{s}^{2}\right]: \ddot{\varphi}_{m}$ - motor rotor, $\ddot{\varphi}_{p}$ - pinion, $\ddot{\varphi}_{g}$ - gear, $\ddot{\varphi}_{d}$ - device rotor

$\ddot{\theta}_{p x}$ - angular acceleration of pinion about the $y_{o p}$ axis $\left[\mathrm{rad} / \mathrm{s}^{2}\right]$

$\ddot{\theta}_{g x}$ - angular acceleration of gear about the $y_{o g}$ axis $\left[\mathrm{rad} / \mathrm{s}^{2}\right]$

$\ddot{\theta}_{p y}$ - angular acceleration of pinion about the $x_{o p}$ axis $\left[\mathrm{rad} / \mathrm{s}^{2}\right]$

$\ddot{\theta}_{g y}$ - angular acceleration of gear about the $x_{o g}$ axis $\left[\mathrm{rad} / \mathrm{s}^{2}\right]$

$\ddot{x}_{p}$ - linear acceleration of pinion on plane defined by the $x_{o p}$ axis and pinion axis of rotation $\left[\mathrm{m} / \mathrm{s}^{2}\right]$

$\ddot{x}_{g}$ - linear acceleration of gear on plane defined by the $x_{o g}$ axis and gear axis of rotation $\left[\mathrm{m} / \mathrm{s}^{2}\right]$

$\ddot{y}_{p}$ - linear acceleration of pinion on plane defined by the $y_{o p}$ axis and pinion axis of rotation $\left[\mathrm{m} / \mathrm{s}^{2}\right]$

$\ddot{y}_{g}$ - linear acceleration of gear on plane defined by the $y_{o g}$ axis and gear axis of rotation $\left[\mathrm{m} / \mathrm{s}^{2}\right]$

$M_{c m}=c_{m}\left(\dot{\varphi}_{m}-\dot{\varphi}_{p}\right) r_{m}-$ torque applied on motor coupling from damping [Nm]

$M_{k m}=k_{m}\left(\varphi_{m}-\varphi_{p}\right) r_{m}$-torque applied on motor coupling from stiffness [Nm]

$M_{c p}=c\left(r_{b 1} \dot{\varphi}_{p}+\dot{x}_{p}-r_{b 2} \dot{\varphi}_{g}+\dot{x}_{g}\right) r_{b 1}$-torque applied on pinion from damping [Nm]

$M_{k p}=k\left(r_{b 1} \varphi_{p}+x_{p}-r_{b 2} \varphi_{g}+x_{g}\right) r_{b 1}$-torque applied on pinion from stiffness [Nm]

$M_{c g}=c\left(r_{b 1} \dot{\varphi}_{p}+\dot{x}_{p}-r_{b 2} \dot{\varphi}_{g}+\dot{x}_{g}\right) r_{b 2}$-torque applied on gear from damping [Nm]

$M_{k g}=k\left(r_{b 1} \varphi_{p}+x_{p}-r_{b 2} \varphi_{g}+x_{g}\right) r_{b 2}$ - torque applied on gear from stiffness [Nm]

$M_{c d}=c_{d}\left(\dot{\varphi}_{g}-\dot{\varphi}_{d}\right) r_{d}$-torque applied on device coupling from damping [Nm]

$M_{k d}=k_{d}\left(\varphi_{g}-\varphi_{d}\right) r_{d}$-torque applied on device coupling from stiffness [Nm]

$M_{f p}=F_{f} r_{f p}$-torque applied on pinion from tooth friction [Nm]

$M_{f g}=F_{f} r_{f g}$-torque applied on gear from tooth friction $[\mathrm{Nm}]$

$F_{n}=k\left(r_{b 1} \varphi_{p}+x_{p}-r_{b 2} \varphi_{g}+x_{g}\right)+c\left(r_{b 1} \dot{\varphi}_{p}+\dot{x}_{p}-r_{b 2} \dot{\varphi}_{g}+\dot{x}_{g}\right)-$ normal meshing force [N]

$F_{f}-$ tooth friction force $[\mathrm{N}]$

$F_{d}=\sqrt{F_{n}^{2}+F_{f}^{2}}-$ dynamic meshing force $[\mathrm{N}]$

$r_{f}$ - moment arm of sliding friction force $[\mathrm{m}]$

$F_{k b 1 x}=k_{b 1} x_{b 1}-$ reaction force of Bearing 1 from stiffness parallel to the $x($ LOA) axis [N] (Subscript 2, 3, $4-$ Bearing 2,

Bearing 3, Bearing 4)

$F_{c b 1 x}=c_{b 1} \dot{x}_{b 1}-$ reaction force of Bearing 1 from damping parallel to the $x($ LOA $)$ axis [N]

\section{REFERENCES}

1. Chen Z., Zhou Z., Zhai W., Wang K. Improved analytical calculation model of spur gear mesh excitations with tooth profile deviations. Mechanism and Machine Theory, 149, 2020, 103838. https:// doi.org/10.1016/j.mechmachtheory.2020.103838.

2. Sánchez M.B., Pleguezuelos M., Pedrero I.J. Approximate equations for the meshing stiffness and the load sharing ratio of spur gears including hertzian effects. Mechanism and Machine Theory, 109, 2017, 231-249. http://dx.doi.org/10.1016/j.mechmachtheory.2016.11.014.

3. Lei Y., Liu Z., Wang D., Yang X., Liu H., Lin J.
A probability distribution model of tooth pits for evaluating time-varying mesh stiffness of pitting gears. Mechanical Systems and Signal Processing, 106, 2018, 355-366. https://doi.org/10.1016/j. ymssp.2018.01.005.

4. Luo Y., Baddour N., Liang M. Dynamical modeling and experimental validation for tooth pitting and spalling in spur gears. Mechanical Systems and Signal Processing, 119, 2019, 155-181. https://doi. org/10.1016/j.ymssp.2018.09.027.

5. Su-chul Kim, Sang-gon Moon, Jong-hyeon Sohn, Young-jun Park, Chan-ho Choi, Geun-ho Lee. Macro geometry optimization of a helical gear pair for mass, efficiency, and transmission er- 
ror. Mechanism and Machine Theory, 144, 2020; 103634. https://doi.org/10.1016/j.mechmachtheory.2019.103634.

6. Zhu X., Dai Y., Ma F. Development of a quasi-analytical model to predict the windage power losses of a spiral bevel gear. Tribology International, 146, 2020, 106258. https://doi.org /10.1016/j.triboint.2020.106258.

7. Wen Q., Du Q., Zhai X. A new analytical model to calculate the maximum tooth root stress and critical section location of spur gear. Mechanism and Machine Theory, 128, 2018, 275-286. https://doi. org/10.1016/j.mechmachtheory.2018.05.012.

8. Xie Ch., Hua L., Han Xi., Lan Ji., Wan X., Xiong Xi. Analytical formulas for gear body-induced tooth deflections of spur gears considering structure coupling effect. International Journal of Mechanical Sciences, 148, 2018, 174-190. https://doi. org/10.1016/j.ijmecsci.2018.08.022.

9. Park D., Kolivand M., Kahraman A. Prediction of surface wear of hypoid gears using a semi-analytical contact model. Mechanism and Machine Theory, 52, 2012, 180-194. doi:10.1016/j.mechmachtheory.2012.01.019.

10. Pedro M.T. Marques, Ramiro C. Martins, Jorge H.O. Seabra. Power loss and load distribution models including frictionaleffects for spur and helical gears. Mechanism and Machine Theory, 96, 2016, 1-25. http://dx.doi.org/10.1016/j.mechmachtheory.2015.09.005.

11. Fernandez-del-Rincon, Garcia P., Diez-Ibarbia A., A. de-Juan, Iglesias M., Viadero F. Enhanced model of gear transmission dynamics for condition monitoring applications: Effects of torque, friction and bearing clearance. Mechanical Systems and Signal Processing, 85, 2017, 445-467. http:// dx.doi.org/10.1016/j.ymssp.2016.08.031

12. Fernandez del Rincon, Viadero F., Sancibrian R., Garcia Fernandez P., A. de Juan. A dynamic model for the study of gear transmissions. WIT Transactions on Modelling and Simulation, Vol 48, 2009 WIT Press. doi:10.2495/CMEM090471.

13. Nevzat Ozguven H., Houser D.R. Mathematical models used in gear dynamics - a review. Journal of Sound and Vibration, 121(3), 1988, 383-411.

14. Howard I., Jia S., Wang J. The dynamic modelling of a spur gear in mesh including friction and a crack. Mechanical Systems and Signal Processing, 15(5), 2001, 831-853

15. Mohammed O.D., Rantatalo M., Jan-Olov Aidanpää. Dynamic modelling of a one-stage spur gear system and vibration-based tooth crack detection analysis. Mechanical Systems and Signal Processing, 54-55, 2015, 293-305. http://dx.doi. org/10.1016/j.ymssp.2014.09.001.

16. Bartelmus W. Mathematical modelling and computer simulations as an aid to gearbox diagnostics, Mechanical Systems and Signal Processing, 15(5), 2001, 855-871. doi:10.1006/mssp.2001.1411.

17. Bartelmus W., Chaari F., Zimroz R., Haddar M. Modelling of gearbox dynamics under time-varying nonstationary load for distributed fault detection and diagnosis. European Journal of Mechanics A/Solids, 29, 2010, 637-646. doi:10.1016/j.euromechsol.2010.03.002.

18. Wu J., Yang Y., Wang P., Wang J., Cheng J. A novel method for gear crack fault diagnosis using improved analytical-FE and strain measurement. Measurement, 163, 2020, 107936. https://doi. org/10.1016/j.measurement.2020.107936.

19. Neubauer P., Bös J., Melz T. Evaluation of the gear noise reduction potential of geometrically uneven inequidistant gears. Journal of Sound and Vibration, 473, 2020, 115234. https://doi.org/10.1016/j. jsv.2020.115234.

20. Ling-Yun Zhu, Jian-Fei Shi, Xiang-Feng Gou. Modeling and dynamics analyzing of a torsional-bending-pendular face-gear drive system considering multi-state engagements. Mechanism and Machine Theory, 149, 2020, 103790. https://doi. org/10.1016/j.mechmachtheory.2020.103790.

21. Yang X., Ding K., He G. Phenomenon-model-based AM-FM vibration mechanism of faulty spur gear. Mechanical Systems and Signal Processing, 134, 2019, 106366. https://doi.org/10.1016/j. ymssp.2019.106366.

22. Shin D., Palazzolo A. Nonlinear analysis of a geared rotor system supported by fluid film journal bearings. Journal of Sound and Vibration, 475, 2020, 115269. https://doi.org/10.1016/j.jsv.2020.115269.

23. Byrtus M. Qualitative analysis of nonlinear gear drive vibration caused by internal kinematic and parametric excitation. Engineering MECHANICS, 15, 2008, 471-480. 